Research Article

\title{
Comparison of the efficacy and safety of norethisterone vs. combined oral contraceptive pills for the management of puberty menorrhagia
}

\author{
Nita K. Patel ${ }^{\mathrm{a}, *}$, Shalin Patel $^{\mathrm{b}}$, Rohit Damor ${ }^{\mathrm{c}}$, Manish R. Pandya ${ }^{\mathrm{d}}$
}

${ }^{\mathrm{a}}$ Assistant Professor, ${ }^{\mathrm{b}} 3^{\text {rd }}$ Year Resident, ${ }^{\mathrm{c}} 2^{\text {nd }}$ Year Resident, ${ }^{\mathrm{d}}$ Professor \& Head, Department of Obstetrics and Gynecology, C.U. Shah Medical College \& Hospital, Surendranagar 363001, India

Received: 8 October 2012

Revised: 30 October 2012

Accepted: 9 November 2012

*Correspondence to:

Dr. Nita K. Patel,

Email: pcpate127@gmail.com

\begin{abstract}
Background: The most common cause of puberty menorrhagia is immaturity of the hypothalamic pituitary ovarian axis. Treatment is directed towards stabilizing the endometrium and treating the hormonal alterations. The objective of this study was to compare the efficacy and safety of norethisterone and combined oral contraceptive (COC) pills for the management of puberty menorrhagia.
\end{abstract}

Methods: A total of 60 young girls from age of menarche to 19 years with menorrhagia were randomized to receive either norethisterone or COC pills. The end points included change from baseline in health-related quality-of-life parameters, estimation of blood loss and effect on hemoglobin level. Healthrelated quality-of-life question scores at baseline and after treatment were calculated as mean for norethisterone group and COC pills group.

Results: Norethisterone and COC pills treatment groups showed mean improvement in Menorrhagia Impact Questionnaire (MIQ) scores compared to baseline. However, the total mean score was higher in norethisterone group compared to COC pills group after three treatment cycles (21 Vs 17). The treatment failure was less in norethisterone group compared to COC pills group.

Conclusions: Use of norethisterone was more effective and better tolerated compared to combined oral contraceptive pills for the management of puberty menorrhagia.

Keywords: Adolescent, Puberty, Menorrhagia, Progesterone, Heavy menstrual bleeding, Combined Oral Contraceptive (COC)

\section{INTRODUCTION}

Puberty menorrhagia is defined as excessive bleeding in amount $(>80 \mathrm{ml})$ or in duration (>7days) between menarche and 19 years of age. ${ }^{1}$ The term puberty is generally used in a more comprehensive sense to refer to the whole period of time during which secondary sexual characteristics develop, menstruation begins in females and psychosexual outlook of a human being changes. The onset of menstruation is influenced by a number of factors like genetics, nutrition, body weight and maturation of the hypothalamic pituitary ovarian axis. ${ }^{2}$ The onset of menstruation does not mean that ovulation has occurred. In the majority, early menstrual cycles are anovulatory. ${ }^{3}$ The cycle length varies for some considerable years after menarche. It may take some 5-8 years before menstrual cycle normality is established. During this time it is common for adolescents to present with menstrual irregularities. ${ }^{2,3}$ The most common cause of puberty menorrhagia is anovulatory cycles, which are related to immaturity of the hypothalamic-pituitary-ovarian axis. ${ }^{4,5}$ Other causes include infection, bleeding disorders, and endocrine disorders (eg, hypothyroidism, polycystic ovary syndrome). ${ }^{5-7}$

Anemia is potential sequelae of puberty menorrhagia. ${ }^{8}$ This sequelae may be prevented with appropriate management of the underlying problem. Therefore, it is important to establish the correct diagnosis before any therapy is administered. ${ }^{9}$

Adolescent girls with gynecological problems require a degree of privacy and sensitive handling, as many of the gynecological problems encountered relate to intimate body functions at a time when the individual is maturing sexually and having to deal with issues that are embarrassing and may be considered taboo. Medical interventions to reduce menstruation include combined 
oral Contraceptive (COC) pills, gonadotrophin-releasing hormone $(\mathrm{GnRH})$ analogues and oral progesterones.

This study was conducted to find out the efficacy and safety of norethisterone and combined oral contraceptive (COC) pills for the management of puberty menorrhagia.

\section{METHODS}

This study was conducted at a single academic medical center, with approval from the Institutional Ethics Committee. A total of 60 young girls from age of menarche to 19 years with history of excessive bleeding per vagina were included in the study. Blood loss during menstruation was considered excessive if the duration of menstruation was more than seven days and/or there was a history of passage of clots and the hemoglobin level was $\leq 10 \mathrm{gm} / \mathrm{dl}$. A detailed history regarding age of patient, age of menarche, previous menstrual history was taken. The presenting complaints about onset, duration and amount of blood loss were noted. The medical history included history of recent weight change, thyroid disorders and hematological disorders. Past surgical history of any excessive bleeding was noted. Personal history included history of any drug intake. Family history was taken in detail regarding presence of any disease like bleeding diathesis and thyroid disease.

The participants were randomly assigned to receive either norethisterone or high dose oral contraceptive pills (containing ethinyl estradiol $50 \mu \mathrm{g}$ ). The allocation sequence was generated using a random number table. The allocation ratio was $1: 1$. Participants were advised to take one tablet of norethisterone acetate $(5 \mathrm{mg})$ twice daily for last 15 days of menstrual cycle or one pill of combined oral contraceptive (OC) for 21 days of menstrual cycle. All participants were advised to take treatment for 3 menstrual cycles according to the randomization. The follow-up was done after 3 menstrual cycles. The end points included change from baseline in health-related quality-of-life parameters, estimation of blood loss and effect on hemoglobin level. Qualitative health-related quality-of-life assessments were based on responses to the Menorrhagia Impact Questionnaire (MIQ) that was completed by participants after initial screening and treatment cycles (Table 1).

Table 1: Menorrhagia Impact Questionnaire (MIQ).

\begin{tabular}{|c|c|}
\hline Questions & Response Options \\
\hline $\begin{array}{l}\text { 1. Do you feel that your social activities have been impaired } \\
\text { because of your menstrual bleeding? }\end{array}$ & $\begin{array}{l}\text { 1. Extremely } \\
\text { 2. Quite a bit } \\
\text { 3. Moderately } \\
\text { 4. Slightly } \\
\text { 5. Not at all }\end{array}$ \\
\hline $\begin{array}{l}\text { 2. Do you feel that your work performance has been impaired } \\
\text { because of your menstrual bleeding? }\end{array}$ & $\begin{array}{l}\text { 1. Extremely } \\
\text { 2. Quite a bit } \\
\text { 3. Moderately } \\
\text { 4. Slightly } \\
\text { 5. Not at all }\end{array}$ \\
\hline $\begin{array}{l}\text { 3. Do you feel tired or exhausted because of your menstrual } \\
\text { bleeding? }\end{array}$ & $\begin{array}{l}\text { 1. Extremely } \\
\text { 2. Quite a bit } \\
\text { 3. Moderately } \\
\text { 4. Slightly } \\
\text { 5. Not at all }\end{array}$ \\
\hline 4. Do you feel less productive during menstruation? & $\begin{array}{l}\text { 1. Extremely } \\
\text { 2. Quite a bit } \\
\text { 3. Moderately } \\
\text { 4. Slightly } \\
\text { 5. Not at all }\end{array}$ \\
\hline 5. Do you feel unclean or unhygienic during menstrual bleeding? & $\begin{array}{l}\text { 1. Extremely } \\
\text { 2. Quite a bit } \\
\text { 3. Moderately } \\
\text { 4. Slightly } \\
\text { 5. Not at all }\end{array}$ \\
\hline 6. Do you feel depressed during menstrual bleeding? & $\begin{array}{l}\text { 1. Extremely } \\
\text { 2. Quite a bit } \\
\text { 3. Moderately } \\
\text { 4. Slightly } \\
\text { 5. Not at all }\end{array}$ \\
\hline
\end{tabular}


Among the parameters measured by the MIQ were impairment in social activities, work performance, physical activities, productivity, hygienic condition, psychological condition. The MIQ was scored on a 1 to 5 point scale (1: Extremely; 5: Not at all). ${ }^{10,11}$ Health-related quality-of-life question scores (MIQ scores) at baseline and after treatment were calculated as mean for norethisterone group and combined oral contraceptive (COC) pills group. The study was conducted in compliance with the principles of the Declaration of Helsinki and guidelines for Good Clinical Practice.

\section{RESULTS}

Both groups had comparable baseline and demographic characteristics. A total of 60 patients were randomized to receive norethisterone $(n=30)$ or combined oral contraceptive (COC) pills $(n=30)$. There was mean improvement in MIQ score for social activities related question in both treatment groups compared to baseline (Table 2).

Table 2: Effects of Norethisterone and Combined Oral Contraceptive (COC) pills on mean MIQ scores.

\begin{tabular}{|cccc|}
\hline \multirow{2}{*}{ Questions } & \multicolumn{3}{c|}{ MIQ Scores } \\
\cline { 2 - 4 } & $\begin{array}{c}\text { Before } \\
\text { treatment }\end{array}$ & \multicolumn{3}{c|}{ After treatment } \\
\cline { 2 - 4 } & 2 & Norethisterone & COC pills \\
\hline Social activities & 2 & 3 & 3 \\
Work performance & 1 & 3 & 2 \\
Tired / Exhausted & 3 & 4 & 2 \\
Feeling productive & 1 & 3 & 4 \\
Unclean / & 3 & 4 & 2 \\
unhygienic & 12 & 21 & 4 \\
Depressed & & 9 & 5 \\
Total & & & 17 \\
Difference & & & 4 \\
\hline
\end{tabular}

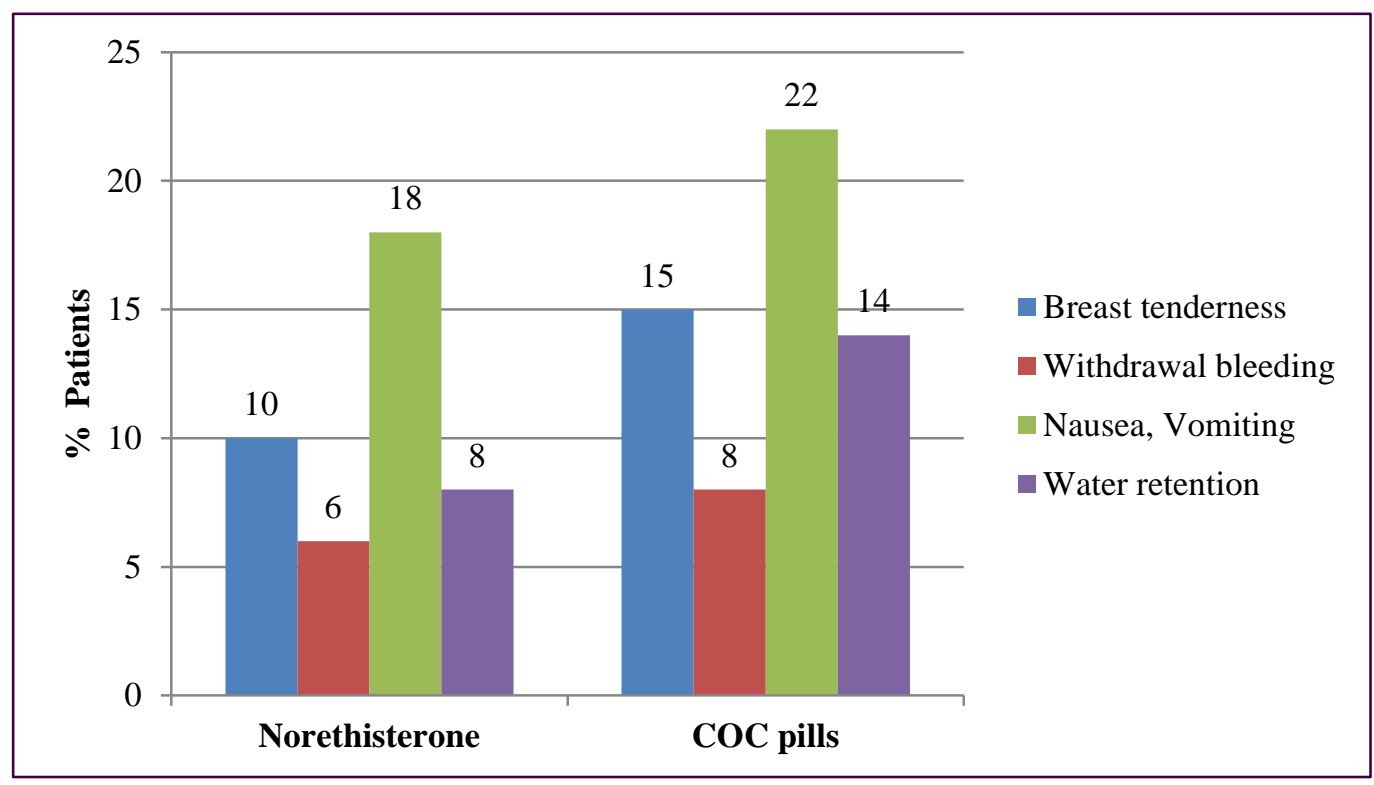

Figure 1: Incidence of adverse effects in Norethisterone and Combined Oral Contraceptive (COC) pills groups. 
For work performance related question, there was mean improvement in norethisterone group compared to baseline. But there was no change in MIQ score for COC pills group compared to baseline in work performance related question (Table 2). There was mean improvement in MIQ scores for tiredness, productiveness, hygienic condition and depressiveness related questions in both treatment groups compared to baseline (Table 2).

Time to treatment failure was longer in norethisterone group compared to COC pills group. $11 \%$ of patients had treatment failure in norethisterone group while treatment failure was reached to $32 \%$ in COC pills group. A decrease in blood loss was more in norethisterone group compared to $\mathrm{COC}$ pills group. There was significant increase in hemoglobin level in norethisterone group compared to COC pills group. Overall, both treatment groups showed mean improvement in MIQ scores compared to baseline (Table 2). However, the total mean score was higher in norethisterone group compared to COC pills group after three treatment cycles (21 Vs 17).

The incidence of some common side effects (breast tenderness, withdrawal bleeding, nausea \& vomiting, water retention) in norethisterone and COC pills groups are shown in figure 1. Norethisterone had better tolerability compared to COC pills in this study.

\section{DISCUSSION}

Puberty menorrhagia can be caused by a number of conditions; the most common cause is immaturity of the hypothalamic pituitary ovarian axis. Treatment is directed towards stabilizing the endometrium and treating the hormonal alterations. First line treatment in mild cases is tranexamic acid and non-steroidal anti-inflammatory agents during the menstrual cycle. Hormonal treatment is required where the girl is anemic or where the problem is recurrent and restricts her activity for 3-6 months.

This study demonstrated that norethisterone and COC pills are effective for the management of puberty menorrhagia. Norethisterone was more effective with better safety profile compared to COC.

Our results agree with published studies in adults that show improvements of menorrhagia during norethisterone use and support the common clinical practice of treating menorrhagia with norethisterone. ${ }^{12-15}$ This study demonstrates that norethisterone or COC pills-mediated improvements in menorrhagia extend to adolescents. Progesterone can be used cyclically in two different treatment Protocols-as short course during luteal phase and a relatively longer course lasting 21 days from day 5 of cycle.

This study has limitations. Methodological limitations in the present study include the small sample size and the absence of blinding. Randomized controlled trials with larger numbers are needed to compare the norethisterone to other medical therapies.

In conclusion, the results of this randomized study support the use of norethisterone and COC pills for the management of puberty menorrhagia. Norethisterone was more effective and better tolerated as compared to COC pills for the management of puberty menorrhagia.

\section{REFERENCES}

1. Caufriez A. Menstrual disorders in adolescence: pathophysiology and treatment. Horm Res 1991;36:156-9.

2. Hallberg L, Hogdahl AM, Nilsson L, Rybo G. Menstrual blood loss- a population study. Variation at different ages and attempts to define normality. Acta Obstet Gynecol Scand 1966;45:320-51.

3. Lemarchand-Beraud T, Zufferey MM, Reymond M, Rey I. Maturation of the hypothalamo-pituitaryovarian axis in adolescent girls. J Clin Endocrinol Metab 1982;54:241-6.

4. Claessens EA, Cowell CA. Acute adolescent menorrhagia. Am J Obstet Gynecol 1981;139:27780.

5. Falcone $\mathrm{T}$, Desjardins $\mathrm{C}$, Bourque J, Granger L, Hemmings R, Quiros E. Dysfunctional uterine bleeding in adolescents. J Reprod Med 1994;39:7614.

6. O'Connell BJ. The pediatrician and the sexually active adolescent. Treatment of common menstrual disorders. Pediatr Clin North Am 1997;44:1391-404.

7. Kadir RA, Economides DL, Sabin CA, Owens D, Lee CA. Frequency of inherited bleeding disorders in women with menorrhagia. Lancet 1998;351:4859.

8. Revel-Vilk S, Paltiel O, Lipschuetz $\mathrm{M}$, et al. Underdiagnosed menorrhagia in adolescents is associated with underdiagnosed anemia. J Pediatr 2012;160:468-72.

9. Bayer SR, DeCherney AH. Clinical manifestations and treatment of dysfunctional uterine bleeding. JAMA 1993;269:1823-8.

10. Patel NK, Pandya MR. A comparative study of tranexamic acid and ethamsylate in menorrhagia. Int J Basic Clin Pharmacol 2012;1:85-90.

11. Lukes AS, Moore KA, Muse KN. Tranexamic acid treatment for heavy menstrual bleeding: A randomized controlled trial. Obstet Gynecol 2010;116:865-75.

12. Abu Hashim H, Alsherbini W, Bazeed $M$. Contraceptive vaginal ring treatment of heavy menstrual bleeding: a randomized controlled trial with norethisterone. Contraception 2012;85:246-52.

13. Irvine GA, Campbell-Brown MB, Lumsden MA, Heikkilä A, Walker JJ, Cameron IT. Randomised comparative trial of the levonorgestrel intrauterine system and norethisterone for treatment of idiopathic menorrhagia. Br J Obstet Gynaecol 1998;105:592-8. 
14. Preston JT, Cameron IT, Adams EJ, Smith SK. Comparative study of tranexamic acid and norethisterone in the treatment of ovulatory menorrhagia. Br J Obstet Gynaecol 1995;102:401-6.
15. Bonduelle M, Walker JJ, Calder AA. A comparative study of danazol and norethisterone in dysfunctional uterine bleeding presenting as menorrhagia. Postgrad Med J 1991;67:833-6.

doi: 10.5455/2319-2003.ijbcp003512

Cite this article as: Patel NK, Patel S, Damor R,

Pandya MR. Comparison of the efficacy and safety of norethisterone vs. combined oral contraceptive pills for the management of puberty menorrhagia. Int $\mathbf{J}$ Basic Clin Pharmacol 2012;1:191-5. 